\title{
Nicolás de Piérola y la articulación con sus agentes en Europa y Centroamérica durante la Guerra del Pacífico (1881-1883)
}

\author{
Julio Abanto Chani \\ Universidad Nacional Mayor de San Marcos \\ julioabanto80@gmail.com
}

\begin{abstract}
RESEÑA
Uno de los principales vacíos de la historiografía peruana sobre la guerra del Pacífico es reconstruir los pasos que dio Nicolás de Piérola en Europa (1882-1884), luego de enfrentarse a diversos escenarios como la caída de Lima, perder la Presidencia de la República en noviembre de 1881 y fundar el efímero Partido Nacional. Cuando Piérola partió hacia Francia (marzo de 1882) adoptó una posición de abstención y de no involucrarse en la guerra. Desde ese momento, no se dispone de mayor información sobre sus operaciones en el extranjero. Por ello, gracias a la información proveniente del Archivo Piérola de la Biblioteca Nacional del Perú, se realizará la reconstrucción de las relaciones de Piérola entre 1881 y 1883 con sus principales colaboradores ubicados en tres países claves para el curso de la guerra: Francia (el diplomático Toribio Sanz), Inglaterra (el almirante Aurelio García y García) y Panamá (el coronel y cónsul general Federico Larrañaga).
\end{abstract}

Palabras clave: Guerra del Pacífico (1879-1883); Nicolás de Piérola; historia diplomática; servicio diplomático del Perú; agentes privados y corresponsales.

\section{Nicolás de Piérola and the articulation with his agents in Europe and Central America during the War of the Pacific (1881-1883)}

\begin{abstract}
One of the main gaps in Peruvian historiography on the Pacific War is to reconstruct the steps taken by Nicolás de Piérola in Europe (1882-1884), after facing various scenarios such as the fall of Lima, losing the Presidency of the Republic in November 1881 and founding the short-lived National Party. When Piérola left for France (March 1882) he adopted a position of abstention and did not get involved in the war. Since that time, no further information is available on its operations abroad. Therefore, thanks to the information from the Piérola Archive of the National Library of Peru, the reconstruction of Piérola's relations between 1881 and 1883 will be carried out with his main collaborators located in three key countries for the course of the war: France (the diplomat Toribio Sanz), England (Admiral Aurelio García y García) and Panama (Colonel and Consul General Federico Larrañaga).
\end{abstract}

Keywords: War of the Pacific (1879-1883); Nicolás de Piérola; Diplomatic History; Diplomatic Service of Peru; Private agents and correspondents. 


\section{Introducción. Nicolás de Piérola, la disputa del poder tras la caída de Lima en manos del ejército chileno y su salida al extranjero en 1882}

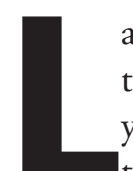

a historia diplomática es una disciplina que tiene larga data en la historiografía peruana y una de sus dimensiones de estudio se nutre principalmente del análisis de la correspondencia oficial sostenida entre el Ministerio de Relaciones Exteriores y sus legaciones y consulados repartidos en diversos continentes. Particularmente, sobre el tema de la Guerra del Pacífico contamos con investigaciones de Daniel Parodi sobre el papel de Bolivia y Lizardo Montero tras la caída de Lima (2001), José Ballón sobre el rol de Estados Unidos durante la guerra ${ }^{1}$ (2006), Ronald Bruce con una visión panorámica de la política exterior peruana desde el siglo XIX (1999), Rosa Garibaldi con una selección de importantes episodios diplomáticos como el que tuvo el Perú con Costa Rica (2013), Hugo Pereyra rastreando los orígenes del tratado de Ancón en la correspondencia de José Antonio de Lavalle (2015), José de la Puente Candamo y José de la Puente Brunke con el rescate de la acción de la Delegación de Lima tras el aprisionamiento del presidente García Calderón, y Julio Abanto con artículos sobre el papel de las legaciones peruanas en Colombia (2017a), Estados Unidos (2014), Bolivia y Argentina (2013, 2017 b y 2017c), y Costa Rica (2019).

Esto muestra el potencial de la historia diplomática para comprender procesos tan complejos como la guerra y en especial, un aspecto poco explorado: la migración de líderes políticos y la articulación de redes de información para influenciar políticamente sobre el destino de uno de los países beligerantes, como fue el Perú. Para comprender el caso de Nicolás de Piérola, su salida del Perú y cómo pudo establecer canales de comunicación en Europa y Centroamérica, es necesario hacer un breve recuento de los hechos que precipitaron su salida hacia París.

Tras la caída de Lima en enero de 1881 apreciamos un escenario político que colocó en punto de colisión a dos presidentes peruanos que regían los destinos del país de forma paralela: Nicolás de Piérola por un lado y Francisco García Calderón por otro.

1 Jose Ballón. Blaine y Martí en la dialéctica de la Guerra del Pacifico (2006).
Piérola había instaurado una dictadura en diciembre de 1879, centralizando las funciones militares y legislativas. Al caer Lima partió de inmediato a Junín para reorganizar sus fuerzas militares con Andrés A. Cáceres a la cabeza y reafirmar la alianza con Bolivia. También convocó a una Asamblea Nacional que se reunión en la ciudad de Ayacucho, la que aceptó su renuncia a la dictadura y lo proclamó como nuevo presidente del Perú (Abanto: 2017, 65-69).

Por su parte, García Calderón fue nombrado presidente provisorio por una alianza política financiera compuesta por el Partido Nacional (pradista), el Partido Civil y el club salitrero. Convocó al Congreso de Chorrillos que lo confirmó en su alto puesto y envió expediciones militares para instalar a sus nuevas autoridades en el norte (Áncash, a cargo de Isaac Recabarren), el centro (Junín, a cargo del general Manuel González de la Cotera) y el sur (Ayacucho y Arequipa). No obstante, todas acabaron pésimamente y hundieron en el descrédito a su bisońo gobierno (Abanto: 2012, 64-71). Entonces, si el régimen de García Calderón se encontraba debilitado y a punto de desaparecer, ¿qué factores influyeron para que este se repusiera y arrasara prácticamente con el gobierno pierolista, obligándolo a renunciar al mando y confinándolo en Lima?

Llegado a este punto, debemos resaltar que el panorama de anarquía política e incertidumbre fue despejada por la intervención de un agente externo durante el primer semestre de 1881: la participación de los Estados Unidos con una mediación diplomáti$\mathrm{ca}$, proponiendo e imponiendo una paz sin cesión territorial favorable para el Perú, por lo que no perdería la provincia litoral de Tarapacá y sus ricas salitreras, fuente de la hegemonía socioeconómica de la burguesía limeña y actor que movilizó a la alianza que creó el Gobierno de García Calderón. El envío del nuevo ministro plenipotenciario de los Estados Unidos en el Perú, general Stephen Hurlbut, cambió drásticamente la arena política peruana al reconocer oficialmente a García Calderón como gobierno, desconoció al de Piérola y se hicieron más tensas las relaciones con Patricio Lynch, jefe de las fuerzas chilenas en Lima. De esta manera, el ansiado objetivo de unificar al país se cumplió y fue encabezado por García Calderón, quien logró el respaldo de las fuerzas militares del norte, centro y sur a fines de 1881 (Abanto: 2012, 76-86). Abandonado por el ejército y los principales 
jefes militares, Piérola renunció a la Presidencia de la República el 28 de noviembre de 1881.

Pero, todo este despliegue político basado en el apoyo desde el extranjero no fue sino un espejismo, que vino y se fue rápidamente porque el presidente estadounidense J. Garfield sufrió un atentado que produjo su muerte semanas después, dejando fuera al principal motor y cerebro de esta alianza de la Casa Blanca con García Calderón: el secretario de Estado James Blaine. Esto provocó una crisis política en el Perú: se capturó y tomó prisionero al presidente García Calderón el 6 de noviembre de 1881. Asumió el mando como primer vicepresidente el almirante Lizardo Montero, quien se encontraba en la región de Cajamarca e inició su gestión en plena coordinación con la recién conformada Delegación del Supremo Gobierno, dirigida por los jóvenes civilistas Manuel Candamo y Carlos Elías. Este órgano administrativo fue clave para la subsistencia y funcionamiento del gobierno de Montero, asentado en Cajamarca hasta febrero de 1882, cuando se trasladó hacia Huaraz (De la Puente Candamo \& De la Puente Brunke: 2016, 37-48).

Mientras tanto, Piérola arribó a Lima en diciembre de 1881 y se entrevistó con Lynch, quien consideraba que debía continuar vigilado y evaluar si podía aprovecharse de su figura para utilizarla en favor de Chile. A inicios de 1882, se fundó el Partido Nacional que reunía a diversas figuras del pierolismo como Ricardo Palma, Antonio Arenas, Aurelio García y García, José Antonio de Lavalle, entre otros. Se ha verificado que hubo un intento de acercamiento entre los pierolistas con los miembros del Partido Civil, produciéndose diversas reuniones con Manuel Candamo; pero finalmente no se llegó a ningún acuerdo o resultado positivo (De la Puente Candamo \& De la Puente Brunke: 2009, 681-686).

Tras el fracaso de esta reunión que buscaba una respuesta unificada de los partidos políticos, el pierolismo adoptó una posición abstencionista, es decir, se alejaba del camino que tomase el gobierno del almirante Montero en Cajamarca y, paralelamente, Piérola preparó su partida hacia Europa, hacia donde finalmente viajó en marzo de 1882. Para reconstruir este episodio de la estadía de Piérola en Francia y observar la importancia de cómo se integró la decisión de migrar y desarrollar una intensa comunicación con sus agentes y corresponsales en el exterior, analizaremos tres casos de actores que transitaban entre el espectro privado y el público (como miembros del servicio diplomático peruano) entre los años 1881-1883:

- Toribio Sanz. Desarrolló su actividad diplomática en Francia y estableció coordinaciones con Nicolás de Piérola cuando este abandonó el Perú en 1882 y residió en París, ofreciéndole sus conexiones en Francia e Inglaterra hasta su fallecimiento repentino en 1883 .

- Federico Larrañaga. Sus gestiones tuvieron a Panamá como su centro de operaciones, logró administrar el periódico El Canal y buscó conseguir fondos en Venezuela, México y Centroamérica para su sostenimiento entre 1882-1883.

- Aurelio García y García. Efectúo en Londres un trabajo de seguimiento tanto de la política británica y como de la peruana en el marco de la aprobación de las condiciones de paz (1883). Además, fue testigo de la fractura del partido pierolista por la asunción al poder del general Iglesias en el Perú, en enero de 1883.

La reconstrucción de este proceso histórico se realizará sobre la base de la información procedente de las fuentes documentales del Archivo Piérola de la Biblioteca Nacional del Perú. A diferencia de la documentación custodiada por el Archivo del Ministerio de Relaciones Exteriores, que registra comunicaciones oficiales entre los miembros del servicio diplomático del Perú en el extranjero y la Cancillería peruana, la información del Archivo Piérola contiene la correspondencia personal de este expresidente peruano, cursada entre los ańos 1860-1910 con sus agentes privados, representantes y círculo político y familiar más cercano.

Asimismo, la importancia del Archivo Piérola radica en las siguientes razones:

- Es la primera vez que se dispone de un archivo casi completo de un presidente de la República. Es importante comprobar que la documentación personal de Piérola intercambiada a lo largo de su carrera política se encuentra centralizada en la Biblioteca Nacional del Perú y disponible para el uso de los investigadores, en especial para analizar el tema de la Guerra del Pacífico.

- Tiene un gran potencial de investigación porque no ha sido examinada por otros estudios sobre la 
guerra con Chile. Tras revisar bibliografía especializada y tesis universitarias se ha podido verificar que la información proveniente del Archivo Piérola no ha sido consultada ni utilizada por los trabajos clásicos del Centenario (1979) ni los más recientes (año 2000 en adelante), es decir, representa un importante vacío para la historiografía peruana.

\section{Las gestiones del diplomático Toribio Sanz en Francia (1881-1883)}

\section{La caída de Lima, dos presidentes paralelos y la renuncia de Piérola (1881)}

No se conoce mucho sobre la biografía de Toribio Sanz, pero tuvo un papel clave durante la guerra. ¿Por qué le encargó Piérola una misión diplomática tan importante como la de Francia, Inglaterra y España en 1880 ? Ese año, Sanz cumplió un importante papel en la economía (guano y salitre) y obtención de armas para el Perú. Pero, eso cambiaría radicalmente al ańo siguiente, pues en sus cartas personales, como todos los miembros del servicio diplomático peruano, Sanz informaba a Piérola que en enero de 1881 estaba a la expectativa del avance del ejército chileno por Lurín y que pronto darían inicio las batallas decisivas por el control de $\mathrm{Lima}^{2}$. Sin embargo, tuvo una honda sorpresa cuando se enteró de los resultados negativos en San Juan y Miraflores. Los días posteriores a la derrota le causaron mayor preocupación por la ocupación de la capital y la partida de Piérola a Junín ${ }^{3}$. Aun así, se mantenía atento a cualquier movimiento de armas y naves que Chile hiciese desde Londres ${ }^{4}$.

Asimismo, Sanz intentó conseguir nuevos fondos económicos y reactivó las negociaciones por la explotación del guano con la Sociedad de Crédito Industrial de París y posteriormente con las casas comerciales Dreyfus y la Peruvian Guano Company 5

2 Biblioteca Nacional del Perú; en adelante, BNP. Archivo Piérola. Sobre 5000000857. Carta de Toribio Sanz a Nicolás de Piérola. París, 15 de enero de 1881.

3 BNP. Archivo Piérola. Sobre 5000000857. Carta de Toribio Sanz a Nicolás de Piérola. París, 15 de febrero de 1881.

4 BNP. Archivo Piérola. Sobre 5000000857. Carta de Toribio Sanz a Nicolás de Piérola. París, 31 de enero de 1881.

5 BNP. Archivo Piérola. Sobre 5000000857. Carta de Toribio Sanz a Nicolás de Piérola. París, 28 de febrero de 1881.
Esta última presionaría a Sanz, quien ante la situación agobiante en la que se encontraba el Perú ${ }^{6}$, le propuso administrar su propio cargamento de guano ${ }^{7}$. Por otro lado ante la irrupción de Francisco García Calderón como presidente paralelo a Piérola y el nuevo escenario político, Sanz recomendó realizar la convocatoria a un nuevo Congreso ${ }^{8}$, mientras él intentaba una nueva mediación de Inglaterra y Francia ${ }^{9}$, aunque sus agentes diplomáticos en el Perú no podían dar ningún paso si es que antes sus respectivas Cancillerías no los autorizaban para actuar ${ }^{10}$. Sin embargo, esta mediación sería imposible a corto plazo $^{11}$, por lo que el Perú estaba a merced de las condiciones de paz de Chile.

Por otro lado, transcurría el ańo 1881 y era fundamental mantener la comunicación entre París y Ayacucho, la nueva sede del gobierno pierolista, por lo que Sanz se preocupaba por si su correspondencia fuera interceptada y cayese en manos chilenas, pues ahora controlaban las oficinas de correos de Lima y el Callao; lo que finalmente ocurrió en junio de $1881^{12}$. Además, Sanz le pedía a Piérola que no se hiciesen más giros a nombre de la legación peruana en Francia porque desde París él no tenía las condiciones económicas para atenderlos y era la única fuente para el Perú de fondos en el extranjero ${ }^{13}$.

Mientras tanto, el gobierno de García Calderón venía buscando el reconocimiento internacional ante el cuerpo diplomático en Lima ${ }^{14}$. Al inicio no lo logró, pero luego con el apoyo de Estados Unidos y la acción financiera de la Sociedad General Crédito Industrial (contrato Rosas - Goyeneche) ${ }^{15}$, se impu-

6 BNP. Archivo Piérola. Sobre 5000000857. Carta de Toribio Sanz a Nicolás de Piérola. París, 31 de marzo de 1881.

7 BNP. Archivo Piérola. Sobre 5000000857. Carta de Toribio Sanz a Nicolás de Piérola. Bolougne, 16 de agosto de 1881.

8 BNP. Archivo Piérola. Sobre 5000000857. Carta de Toribio Sanz a Nicolás de Piérola. París, 15 de abril de 1881.

9 BNP. Archivo Piérola. Sobre 5000000857. Carta de Toribio Sanz a Nicolás de Piérola. París, 30 de abril de 1881.

10 BNP. Archivo Piérola. Sobre 5000000857. Carta de Toribio Sanz a Nicolás de Piérola. París, 15 de mayo de 1881.

11 BNP. Archivo Piérola. Sobre 5000000857. Carta de Toribio Sanz a Nicolás de Piérola. París, 31 de mayo de 1881.

12 BNP. Archivo Piérola. Sobre 5000000857. Carta de Toribio Sanz a Nicolás de Piérola. París, 15 de junio de 1881.

13 BNP. Archivo Piérola. Sobre 5000000857. Carta de Toribio Sanz a Nicolás de Piérola. París, 31 de julio de 1881.

14 BNP. Archivo Piérola. Sobre 5000000857. Carta de Toribio Sanz a Nicolás de Piérola. París, 30 de junio de 1881.

15 BNP. Archivo Piérola. Sobre 5000000857. Recibida en Lima diciembre 10 de 1881 
so sobre el régimen de Piérola. La inclusión de esta última compañía dejó fuera a otras empresas deseosas de administrar el guano y salitre peruano como la Peruvian Guano y la Compañía del Pacífico ${ }^{16}$. El juego internacional desplegado por García Calderón que incluyó a Francia y Estados Unidos se convirtió en una real amenaza para Chile ${ }^{17}$, por lo cual fue tomado prisionero y desterrado a Rancagua. Sanz lamentaba toda la crisis política que terminó con la asunción del almirante Montero como vicepresidente y la renuncia de Piérola en noviembre de $1881^{18}$.

\section{Piérola parte hacia Francia y el seguimiento a la política británica (1882-1883)}

A pesar de la renuncia de Piérola, Sanz no dejó el puesto en la legación del Perú en Francia, Inglaterra y España; a pesar de que Montero había nombrado en su reemplazo a Francisco Rosas en febrero de $1882^{19}$. Sanz continúo con las conversaciones con la Compañía Financiera y Comercial del Pacífico para recibir 8000 libras esterlinas como parte de la deuda que se tenía con el Perú ${ }^{20}$ y a la vez reconoció la influencia que tuvo Estados Unidos con el fin del gobierno de Piérola y con su partida hacia Europa. Pero, para 1882 nuevos cambios políticos ocurrían en ese país y culminaron con la renuncia e investigación en el Congreso del secretario de Estado, J. Blaine ${ }^{21}$. Aun así, el civilismo y el gobierno de Montero consideraron que todavía era posible obtener alguna ventaja de algún apoyo diplomático norteamericano.

Cuando Piérola tomó la decisión de migrar hacia Europa, fue una noticia que tomó por sorpresa a Sanz, quien debió organizarse para facilitar su instalación y estadía en París ${ }^{22}$. La pregunta obvia que emerge es: ¿̇de dónde provendrían los medios econó-

16 BNP. Archivo Piérola. Sobre 5000000857. Carta de Toribio Sanz a Nicolás de Piérola. París, 31 de octubre de 1881

17 BNP. Archivo Piérola. Sobre 5000000857. Carta de Toribio Sanz a Nicolás de Piérola. París, 15 de noviembre de 1881.

18 BNP. Archivo Piérola. Sobre 5000000857. Carta de Toribio Sanz a Nicolás de Piérola. París, 30 de noviembre de 1881

19 Oficio de la Delegación del Supremo Gobierno a Francisco Rosas. Lima, 14 de febrero de 1882. No 21. De la Puente Candamo y De la Puente Brunke. Pág. 309

20 BNP. Archivo Piérola. Sobre 5000000857. Carta de Toribio Sanz a Nicolás de Piérola. París, 30 de enero de 1882.

21 BNP. Archivo Piérola. Sobre 5000000857. Carta de Toribio Sanz a Nicolás de Piérola. París, 15 de enero de 1882.

22 BNP. Archivo Piérola. Sobre 5000000857. Carta de Toribio Sanz a Nicolás de Piérola. París, 05 de abril de 1882. micos para la subsistencia del Piérola en un país con un alto costo de vida, sin oficio, con la necesidad de establecer redes y relaciones sociales para no quedar aislado y a la vez sin perder el estatus social de expresidente del Perú? Esta es una interrogante que aún no tiene respuesta.

Ahora bien, desde el Perú llegaban noticias de las importantes victorias del general Andrés A. Cáceres en las batallas de Marcavalle, Pucará y Concepción (julio de 1882). Esto entusiasmó a Sanz y le indicó a Piérola que sería conveniente involucrar en futuras operaciones de la campaña de resistencia a la ciudad de Lima ${ }^{23}$. Estas derrotas chilenas (sumadas a las de San Pablo en Cajamarca) obligaron a Chile a aplicar duras represalias contra los pueblos que osaron enfrentarse al ejército chileno, enviando al destierro a políticos peruanos y cambiando drásticamente su política exterior con el Perú.

Esta coyuntura obligó a Piérola a tomar una nueva posición desde Europa en último trimestre de 1882 y lo obligó a cuestionar su posición de abstención política, por lo que se decidió realizar un viaje a Estados Unidos con dos objetivos: entrevistarse con el nuevo secretario de Estado, Mr. Frelinghuysen, y evaluar un posible retorno al Perú para reasumir el poder y conocer la opinión del gobierno chileno sobre esta idea. En ese mismo periodo, el almirante Montero se había trasladado a Arequipa y Miguel Iglesias apareció como un nuevo caudillo en el norte.

Antes de partir hacia Nueva York, Piérola le pidió a Sanz que le concertara entrevistas con dos figuras relevantes de la política británica: Lord Granville (primer ministro de Inglaterra) y Sir Charles Dilcke (parlamentario) ${ }^{24}$. Para lograrlo, Sanz continúo utilizando sus credenciales como diplomático, a pesar de que ya no lo era oficialmente, pues Francisco Rosas ya ejercía como nuevo jefe de la legación del Perú en Europa. Estas entrevistas no llegaron a producirse en las fechas que Piérola necesitaba ${ }^{25}$. Pero, Sanz a través de sus relaciones, intentaría nuevamente programarlas antes de su viaje a Estados Unidos ${ }^{26}$. Por lo que

23 BNP. Archivo Piérola. Sobre 5000000857. Carta de Toribio Sanz a Nicolás de Piérola. Bolougne, 29 de agosto de 1882.

24 BNP. Archivo Piérola. Sobre 5000000857. Carta de Toribio Sanz a Nicolás de Piérola. Bologne, 02 de setiembre de 1882.

25 BNP. Archivo Piérola. Sobre 5000000857. Carta de Toribio Sanz a Nicolás de Piérola. Bologne, 05 de setiembre de 1882.

26 BNP. Archivo Piérola. Sobre 5000000857. Carta de Toribio Sanz a Nicolás de Piérola. Bologne, 8 de setiembre de 1882 . 
viajó rápidamente a Londres en setiembre de $1882^{27}$, pero el resultado no fue el esperado porque no pudo ubicar a Granville y Dilke no conocía la situación del Perú ${ }^{28}$. Días después, Sanz intentó obtener una cita con Granville $e^{29}$. ¿Por qué era primordial para Piérola lograr conferenciar con ambos políticos ingleses? Es posible que Piérola quisiese conocer su opinión sobre la posición de Inglaterra en la Guerra del Pacífico

Finalmente, para el último trimestre de 1882 enrumbaría hacia los Estados Unidos y no logró modificar la posición de intervención favorable a Chile y tampoco regresó al Perú. Como vemos, Sanz fue una pieza fundamental como diplomático y agente privado. Sin embargo, Piérola perdió a este valioso aliado y sus redes sociales cuando falleció en abril de 1883 . Vivó entre los ańos de 1817-1883 y sus restos descansan en el Passy Cemetery (29-31 Avenue Georges Mandel). Paris, Passy, Ile de Francia ${ }^{30}$.

\section{Las gestiones del coronel y cónsul general Federico Larrañaga en Panamá (1881-1883)}

\section{La caída de Lima y la fundación del periódico El Canal: un periódico peruano en Centroamérica (1881)}

Panamá fue otra de las plazas importantes para el Perú en el plano diplomático porque conectaba a nuestro país con el extranjero (la otra vía de comunicación en América del Sur era por el Estrecho de Magallanes) y era también el principal centro de acopio y distribución de las armas que recibió nuestro país en la guerra con Chile. Norman Guice fue uno de los primeros investigadores que estudió en 1982 las actividades de Larrañaga en Panamá, registrando sus comunicaciones con Ricardo Palma (Sirius) dirigidas al periódico El Canal. Recientemente su trabajo fue referenciado por el historiador Gerardo Trillo (2015).

Para enero de 1881, la situación era tensa porque Lima se batía ante las fuerzas chilenas y el coronel

27 BNP. Archivo Piérola. Sobre 5000000857. Carta de Toribio Sanz a Nicolás de Piérola. Bolougne, 14 de setiembre de 1882.

28 BNP. Archivo Piérola. Sobre 5000000857. Carta de Toribio Sanz a Nicolás de Piérola. Bolougne, 16 de setiembre de 1882 .

29 BNP. Archivo Piérola. Sobre 5000000857. Carta de Toribio Sanz a Nicolás de Piérola. Bolougne, 15 de setiembre de 1882.

30 BillionGraves. https://billiongraves.com/grave/Toribio-deTejada/18307577\# Consultado el 1 de diciembre de 2019.
Federico Larrañaga era en ese momento cónsul general del Perú en la ciudad de Panamá, cargo que ejercía desde 1879 tras ser puesto en libertad por haber participado en una revuelta pierolista contra el gobierno del presidente Prado ${ }^{31}$. Justamente, en medio del fragor de los días previos a la batalla de San Juan (13 de enero de 1881), Larrañaga continúo enviando material bélico y logístico hacia el Perú ${ }^{32}$, pero sus planes quedaron completamente paralizados hasta saber el desenlace de los combates. Simultáneamente, Larrañaga venía trabajando en un nuevo proyecto que incluía la refacción de la imprenta del diario $E l$ Hispanoamericano, dejándolo apto para competir con La Estrella y el Star \& Herald, los principales periódicos de Panamá33.

Al enterarse de la caída de Lima, Larrañaga siguió brindando su apoyo y reconocimiento a Piérola, pero le dolía enormemente la derrota. Pero, no solo por lo que significaba tamaña noticia para el Perú, sino por todo el esfuerzo que había empeñado desde Panamá y que al final no tuvo un resultado satisfactorio por las pésimas decisiones de los estrategas políticos: «iCuánto esfuerzo, cuánto sacrificio perdido! Quiera Dios que estos terribles sucesos sean lección eterna para nuestros conciudadanos.» ${ }^{34}$ Quizás Larrañaga no era consciente, pero el mismo Piérola fue ese estratega militar y el político que hizo posible el desastre de enero de 1881.

Ahora bien, en este nuevo contexto, el control de las noticias de la guerra era prioritario, considerando que ya no existía una prensa libre en Lima por la incautación y traslado de imprentas de los principales diarios a Santiago. Desde ese instante, Chile monopolizó la administración de la información. Luego de la interrupción de las comunicaciones con Piérola, Larrañaga esperaba iniciar coordinaciones con Lizardo Montero, aún leal a Piérola en Cajamarca, pero no tenía certeza de emprender una nueva campaña militar por carecer de embarcaciones para enviar armas hacia Piura ${ }^{35}$ y porque no disponía de fon-

31 Archivo Histórico Riva Agüero. El Bien Público. Año II. Lima, sábado 31 de mayo de 1884.

32 BNP. Archivo Piérola. Sobre 5000000862. Carta de Federico Larrańaga a Nicolás de Piérola. Panamá, 12 de enero de 1881.

33 BNP. Archivo Piérola. Sobre 5000000862. Carta de Federico Larrañaga a Nicolás de Piérola. Panamá, 26 de enero de 1881.

34 BNP. Archivo Piérola. Sobre 5000000862. Carta de Federico Larrañaga a Nicolás de Piérola. Panamá, 9 de febrero de 1881.

35 BNP. Archivo Piérola. Sobre 5000000862. Carta de Federico Larrańaga a Nicolás de Piérola. Panamá, 14 de febrero de 1881. 
$\operatorname{dos}^{36}$. Aun así, Larrañaga le afirmó a Piérola que sí llegó a remitirle a Montero armas (julio de 1881) ${ }^{37}$.

Una de las principales actividades que realizó Larrañaga en Panamá fue la actividad periodística en el diario El Canal: gestionando el local y la imprenta, la contratación del administrador y redactores, verificar las suscripciones, distribución y circulación, etcétera. ¿Cómo lo haría? Larrañaga no contaba con fondos suficientes para una empresa de esa envergadura. Casi de forma milagrosa, Larrañaga obtuvo 5000 libras esterlinas que había solicitado a Toribio Sanz, diplomático peruano en Francia, y con ese monto impulsó la creación de El Canal para difundir la posición pierolista y enfrentarse con El Orden de Lima (periódico de García Calderón) y al diario chileno La Actualidad ${ }^{38}$. Pronto, El Canal tendría todo listo para imprimir nuevas ediciones en inglés y francés, y convocando a un nuevo editor como José Toribio Polo y a un antiguo redactor de "Le Petit Paresiene»"

Sin embargo, ¿sabía realmente Sanz que el dinero entregado era para fundar un nuevo periódico y que eso era una verdadera prioridad para Piérola? Tras revisar la correspondencia de Larrañaga, se puede observar que las libras esterlinas que recibió fue más una decisión unilateral y no fue consultado directamente con Piérola. Esa cifra era a todas luces exorbitante para cualquier funcionario peruano en ese momento de crisis $^{40}$. Consciente quizás de este detalle, Larrańaga no desaprovechó en pedirle reiteradamente a Piérola que aprobase la inversión en la creación de El Canal ${ }^{41}$ y que no debía considerarse como malversación de fondos públicos, sino que lo hizo por un ánimo patriótico y lealtad al dictador, pidiéndole ser reemplazado por otra persona en Panamá ${ }^{42}$.

En marzo de 1881, Miguel Grace, dueño de una importante casa comercial en Estados Unidos y proveedor de armas para el Perú, fue elegido alcalde de

36 BNP. Archivo Piérola. Sobre 5000000862. Carta de Federico Larrańaga a Nicolás de Piérola. Panamá, 2 de marzo de 1881.

37 BNP. Archivo Piérola. Sobre 5000000862. Carta de Federico Larrańaga a Nicolás de Piérola. Panamá, 27 de julio de 1881. N 20

38 BNP. Archivo Piérola. Sobre 5000000862. Carta de Federico Larrañaga a Nicolás de Piérola. Panamá, 23 de marzo de 1881.

39 BNP. Archivo Piérola. Sobre 5000000862. Carta de Federico Larrañaga a Nicolás de Piérola. Panamá, 27 de abril de 1881.

40 BNP. Archivo Piérola. Sobre 5000000862. Carta de Federico Larrañaga a Nicolás de Piérola. Panamá, 2 de marzo de 1881.

41 BNP. Archivo Piérola. Sobre 5000000862. Carta de Federico Larrañaga a Nicolás de Piérola. Panamá, 13 de abril de 1881.

42 BNP. Archivo Piérola. Sobre 5000000862. Carta de Federico Larrañaga a Nicolás de Piérola. Panamá, 05 de octubre de 1881.
Nueva York y arribó a Panamá, siendo recibido por Larrańaga ${ }^{43}$. Grace se encontraba en marcha Chile donde lo aguardaban asuntos comerciales y le pedía a Piérola entrevistarse con él ${ }^{44}$. Y es que en un futuro cercano, Grace sería uno de los principales actores económicos en el Perú porque en 1888 se suscribió un tratado para cancelar la deuda externa peruana tras la guerra del Pacífico, y que se conoció como el contrato Grace.

En abril de 1881, le explicaba a Piérola que Francisco de Paula Suárez iba hacia Lima como agente de la Sociedad General de París para celebrar un nuevo contrato de guano y salitre, pero a último momento este se decidió por negociar solo con García Calderón, quien aceptó de inmediato este contrato para disponer de fondos que no tenía y que necesitaba con urgencia. Mientras tanto, se profundizaba el enfrentamiento entre García Calderón y Piérola, Larrańaga aprovechaba El Canal para criticar al primero, sosteniendo que su gobierno era entreguista y para ello contó con el apoyo de Ricardo Palma como articulista ${ }^{45}$.

Por otro lado, Larrañaga escribía con regularidad a Piérola solicitándole instrucciones para regular sus actividades, pero recibirlas era prácticamente imposible: Piérola se dirigió a Arequipa y luego a La Paz. Esta incomunicación dejó desorientado a Larrañaga en la ejecución de sus proyectos, afirmando que "como un marinero sin compás, sin rumbo, he pedido órdenes a us, a Montero, a Solar, nada, nada.» ${ }^{46}$ Esas quejas irían en aumento en la medida en que transcurrían los meses porque le interesaba saber si debía vender las armas y municiones que tenía almacenados en Panamá ${ }^{47}$ y saber del destino que tendría El Canal, por lo que venía buscando suscriptores y recibiendo avisos de Francia, Inglaterra y Estados Unidos ${ }^{48}$.

43 BNP. Archivo Piérola. Sobre 5000000862. Carta de Federico Larrañaga a Nicolás de Piérola. Panamá, 1 de marzo de 1881.

44 BNP. Archivo Piérola. Sobre 5000000862. Carta de Federico Larrańaga a Nicolás de Piérola. Panamá, 15 de marzo de 1881.

45 BNP. Archivo Piérola. Sobre 5000000862. Carta de Federico Larrañaga a Nicolás de Piérola. Panamá, 7 de abril de 1881.

46 BNP. Archivo Piérola. Sobre 5000000862. Carta de Federico Larrańaga a Nicolás de Piérola. Panamá, 12 de mayo de 1881. N 19

47 BNP. Archivo Piérola. Sobre 5000000862. Carta de Federico Larrańaga a Nicolás de Piérola. Panamá, 20 de abril de 1881. N 15

48 BNP. Archivo Piérola. Sobre 5000000862. Carta de Federico Larrańaga a Nicolás de Piérola. Panamá, 04 de mayo de 1881. N 18 


\section{La sobrevivencia de Larrañaga en Panamá y el fin de El Canal (1882-1883)}

El año 1882 sería crucial para la vida de El Canal. A inicios de año, Larrañaga tomó la decisión de separar a José Toribio Polo de la dirección del periódico por las desavenencias surgidas y propuso como nuevo director a Arturo García ${ }^{49}$. Este fue el primer síntoma que anunciaría las dificultades para administrar un medio de comunicación en el extranjero y no contar con el financiamiento necesario para sostenerlo; por lo que no era descabellado evaluar un posible cierre a corto $_{\text {plazo }}{ }^{50}$. Por otro lado, el gobierno de Montero canceló su nombramiento como cónsul general y designó en su reemplazo a José Antonio Miró Quesada. Este último nunca llegó a ejercer el cargo ni viajó a su destino ${ }^{51}$.

No obstante, para Larrañaga conservar El Canal se convirtió en su única prioridad, ya que era a la vez su medio de subsistencia personal: buscó apoyo en el Perú y el extranjero, pero no obtuvo mayor respues$\mathrm{ta}^{52}$. Llegó hasta evaluar nuevas oportunidades como cuando falleció James Boyd, director del diario «La Estrella de Panamá», se propuso comprar su imprenta para fortalecer a El Canal ${ }^{53}$; por lo que le insistió a Piérola ${ }^{54}$ hacerle un giro de 5000 dólares para pagar la hipoteca y cancelar las deudas del periódico ${ }^{55}$. Para ese momento, todo esfuerzo que realizaba Larrañaga ya no tenía el respaldo de su cargo diplomático ni del gobierno peruano, por lo que proyecto quedó reducido a un esfuerzo individual y personal ${ }^{56}$. Su peor temor era que el mismo Piérola desde Francia lo abandonase a su suerte después de tantos desvelos, por lo que le propuso empeñar en París joyas por un valor

49 BNP. Archivo Piérola. Sobre 5000000862. Carta de Federico Larrańaga a Nicolás de Piérola. Panamá, 24 de enero de 1882.

50 BNP. Archivo Piérola. Sobre 5000000862. Carta de Federico Larrańaga a Nicolás de Piérola. Panamá, 12 de abril de 1882.

51 Oficio de la Delegación del Supremo Gobierno al Ministerio de Relaciones Exteriores. Lima, 23 de enero de 1882. Pág. 305.

52 BNP. Archivo Piérola. Sobre 5000000862. Carta de Federico Larrañaga a Nicolás de Piérola. Panamá, 25 de abril de 1882.

53 BNP. Archivo Piérola. Sobre 5000000862. Carta de Federico Larrañaga a Nicolás de Piérola. Panamá, 21 de mayo de 1882.

54 BNP. Archivo Piérola. Sobre 5000000862. Carta de Federico Larrañaga a Nicolás de Piérola. Panamá, 15 de mayo de 1882.

55 BNP. Archivo Piérola. Sobre 5000000862. Carta de Federico Larrañaga a Nicolás de Piérola. Panamá, 7 de junio de 1882.

56 BNP. Archivo Piérola. Sobre 5000000862. Carta de Federico Larrañaga a Nicolás de Piérola. Panamá, 6 de mayo de 1882. de 12,000 fran $\cos ^{57}$ o remitir un giro de dinero ${ }^{58}$. Ante el silencio de Piérola y de otros compatriotas en Europa y América, Larrańaga tuvo una idea extrema y casi quijotesca: emprendió una serie de viajes por Venezuela $^{59}$, México ${ }^{60}$ y Centroamérica (Costa Rica, Guatemala, Honduras, El Salvador y Nicaragua ${ }^{61}$ para recaudar fondos en favor de la causa peruana y obtener mínimamente un empréstito para el sostenimiento de El Canal.

Nos falta mayor información para conocer los resultados de esta gira realizada por Larrañaga, pero al parecer no obtuvo el resultado que esperaba porque, finalmente, el diario El Canal se perdería y Larrańaga completamente frustrado regresó a Lima en 1883. Abandonó el pierolismo y se adhirió a la causa del general Miguel Iglesias, nuevo presidente de la República, y formó parte de la Asamblea Constituyente de 1884 que reconoció el tratado de paz con Chile, siendo declarado por el Parlamento como Benemérito de la Patria. Murió en Lima ese mismo año ${ }^{62}$.

\section{Las gestiones del almirante Aurelio García y García en Inglaterra (1882-1883)}

\section{Su llegada a Inglaterra, su conexión con Piérola en Paris y la crítica a las bases de paz del presidente Iglesias (1882-1883)}

El caso de Aurelio García y García es un caso bien particular. Él fue un civilista renombrado con experiencia militar, política y diplomática. Sin embargo, durante la guerra con Chile se convirtió en pierolista acérrimo. Tras la caída de Lima (enero de 1881) fue nombrado en ministro general y fue uno de los principales líderes del gobierno de Piérola hasta su

57 BNP. Archivo Piérola. Sobre 5000000862. Carta de Federico Larrañaga a Nicolás de Piérola. Panamá, 11 de junio de 1881.

58 BNP. Archivo Piérola. Sobre 5000000862. Carta de Federico Larrañaga a Nicolás de Piérola. Panamá, 14 de julio de 1882.

59 BNP. Archivo Piérola. Sobre 5000000862. Carta de Federico Larrańaga a Nicolás de Piérola. Panamá, 21 de julio de 1882.

60 BNP. Archivo Piérola. Sobre 5000000862. Carta de Federico Larrańaga a Nicolás de Piérola. Barranquilla, 01 de noviembre de 1882.

61 BNP. Archivo Piérola. Sobre 5000000862. Carta de Benito Neto a Nicolás de Piérola. Panamá, 24 de marzo de 1883.

62 Archivo Histórico Riva Agüero: El Bien Público. Año II. Lima, sábado 31 de mayo de 1884 . 
renuncia en noviembre de $1881^{63}$. Luego de la partida de Piérola a Francia en marzo de 1882 conformó con Antonio Arenas la alta dirección del recientemente creado Partido Nacional y adoptó como su jefe una posición de abstención frente a la guerra. No obstante, mientras avanzaba el tiempo, el estado de desconcierto y crisis interna del partido se hizo más evidente porque Piérola no dejó órdenes precisas de qué hacer frente a los nuevos eventos de la guerra como la resistencia militar del general Cáceres en el centro, el cisma producido por la separación Iglesias en el norte y la inacción del gobierno de Montero en el sur (1882-1883).

En julio de 1882, con motivo de las victorias de Cáceres en Marcavalle, Púcara y Concepción, las fuerzas chilenas iniciaron en Lima la persecución contra políticos peruanos entre pierolistas y civilistas, quienes fueron tomados prisioneros y deportados a Chile. Por esta razón, García y García se vio obligado a salir de forma furtiva hacia Inglaterra, llegando a Liverpool el 27 de marzo de $1883^{64}$, procedente de Nueva York, y luego pasó a la ciudad de Londres ${ }^{65}$. ¿Cómo hizo García y García para llevar su vida y financiar sus actividades en una de las capitales más caras del mundo? Al igual que el caso Piérola en Francia, es otra interrogante que queda abierta.

¿Qué hizo en Londres García y García? Se encargó de realizar denuncias contra las fuerzas chilenas y realizó publicaciones en los principales diarios londinenses (The Times, Daily Telegraph y The Standard) y parisinos (Pall Mall Gazette, Le Temps y La France) porque consideraba fundamental contar con una voz peruana en la prensa del extranjero que contrarrestara la cobertura mediática chilena sobre la guerra del Pacífico En este nuevo frente de guerra, la opinión de Piérola era crucial, por lo que le pedía que no dejara morir a El Canal de Larrañaga ${ }^{66}$.

Chile inició en 1883 negociaciones de paz con el Presidente regenerador Miguel Iglesias, aunque el po-

63 El grado militar de almirante lo obtuvo como parte de una de las leyes dadas por la Asamblea Nacional de Ayacucho. (Abanto: 2017, 96-97).

64 BNP. Archivo Piérola. Sobre 5000000859. Carta de Aurelio García y García a Nicolás de Piérola. Trafalgar, Londres 28 de marzo de 1883.

65 BNP. Archivo Piérola. Sobre 5000000859. Carta de Aurelio García y García a Nicolás de Piérola. Londres, 31 de marzo de 1883.

66 BNP. Archivo Piérola. Sobre 5000000859. Carta de Aurelio García y García a Nicolás de Piérola. Londres, 21 de mayo de 1883. der real que decía tener este gobernante era excesivo ya que no controlaba ninguna región en el norte del Perú, estaba prácticamente encerrado en Cajamarca y era acosado por las fuerzas de José Mercedes Puga, su legendario antagonista ${ }^{67}$. Entonces, ¿cómo sellaría la paz Iglesias sin la intervención de la aliada Bolivia y sin la mediación europea? ¿Cuál sería el destino de las provincias cautivas de Tacna y Arica y el pago de la deuda externa? ${ }^{68}$

Estas negociaciones de paz eran seguidas desde el diario The Times, cuya lectura era imprescindible para conocer los resultados de las conferencias entre el diplomático chileno Jovino Novoa y el delegado peruano José Antonio de Lavalle, expierolista y prisionero en Chile ${ }^{69}$. El producto de estas conversaciones implicarían la pérdida irreparable de Tarapacá, la retención de Tacna y Arica por 10 años y el pago del Perú de su deuda con los acreedores del guano y salitre (Pereyra: 2015, 161-165) ${ }^{70}$. Estas bases fueron aprobadas oficialmente por Santiago en mayo de 1883 y se reconoció a Iglesias como presidente del Perú ${ }^{71}$. En este contexto, García y García lamentó que Lavalle haya consentido esas bases tan lesivas $^{72}$.

Una vez conocidas las bases de paz de NovoaLavalle estas fueron publicadas en el New York Herald. Por su parte, García y García centró su atención en la adhesión que venía recibiendo Iglesias por parte de varios líderes del Partido Nacional como Torrico, Olaechea, Palma, quienes evaluaban apoyarlo para volver al poder nuevamente ${ }^{73}$. Esto obligó a presentar su renuncia a Antonio Arenas, presidente del comité partidario, y evidenció la fractura en el partido por la ausencia de sus principales dirigentes en el Perú (Piérola en Francia y García y García en Inglaterra).

67 BNP. Archivo Piérola. Sobre 5000000859. Carta de Aurelio García y García a Nicolás de Piérola. Londres, 2 de mayo de 1883.

68 BNP. Archivo Piérola. Sobre 5000000859. Carta de Aurelio García y García a Nicolás de Piérola. Londres, 8 de mayo de 1883.

69 BNP. Archivo Piérola. Sobre 5000000859. Carta de Aurelio García y García a Nicolás de Piérola. Londres, 12 de mayo de 1883.

70 BNP. Archivo Piérola. Sobre 5000000859. Carta de Aurelio García y García a Nicolás de Piérola. Londres, 17 de mayo de 1883.

71 BNP. Archivo Piérola. Sobre 5000000859. Carta de Aurelio García y García a Nicolás de Piérola. Londres, 29 de mayo de 1883.

72 BNP. Archivo Piérola. Sobre 5000000859. Carta de Aurelio García y García a Nicolás de Piérola. Londres, 22 de junio de 1883.

73 BNP. Archivo Piérola. Sobre 5000000859. Carta de Aurelio García y García a Nicolás de Piérola. Londres, 2 de julio de 1883. 


\section{La división dentro del pierolismo, el negociado de la Peruvian Guano y la aprobación del tratado de Ancón}

La ruptura del Partido Nacional se haría más evidente cuando las fuerzas chilenas derrotaron a las tropas del general Cáceres en la batalla de Huamachuco (10 de julio de 1883) y terminó por dividir al pierolismo para formar parte del comité iglesista: Lavalle, Torrico, Osma Javier, Barinaga y Calderón ${ }^{74}$. Pero, esta crisis no solo afectó al Partido Nacional sino también al Partido Civil, el cual se reagrupó en torno a la figura de Aurelio Denegri, quien se mostraba indeciso de apoyar a Iglesias ${ }^{75} y$ trató de encontrar una salida a la guerra ${ }^{76}$.

A partir de ese momento, las cartas entre Piérola y García y García se refieren básicamente a la política peruana y a la discusión sobre si Iglesias se convertiría en el presidente que necesitaba el Perú porque su existencia también se encontraba condicionada a la eliminación del gobierno de Lizardo Montero, que desde agosto de 1882 venía rigiendo desde Arequipa y logró instalar un Congreso. Sin embargo, su actividad y actitud dejó mucho que desear porque no llegó a consolidar una política de paz ni de claro apoyo al general Cáceres (Abanto: 2017, 203-216).

Por otro lado, existe un episodio ocurrido en Londres en el que García y García reveló las reuniones que sostenían políticos y diplomáticos civilistas en Inglaterra (Mariano Ignacio Prado, Francisco Rosas y José Francisco Canevaro) (García Belaúnde: 2016, 361-364) y que tenían como objetivo aproPeruvian Guano. Por esta razón, García y García decidió sabotear ${ }^{77}$ estos encuentros, por lo que pidió el apoyo del coronel Jara Almonte, cónsul del Perú en Londres, pero no logró involucrarlo ${ }^{78}$ y posteriormente intentó obligarlo a tomar actitud que evitase

74 BNP. Archivo Piérola. Sobre 5000000859. Carta de Aurelio García y García a Nicolás de Piérola. Londres, 16 de julio de 1883.

75 BNP. Archivo Piérola. Sobre 5000000859. Carta de Aurelio García y García a Nicolás de Piérola. Londres, 23 de agosto de 1883.

76 BNP. Archivo Piérola. Sobre 5000000859. Carta de Aurelio García y García a Nicolás de Piérola. Londres, 7 de setiembre de 1883.

77 BNP. Archivo Piérola. Sobre 5000000859. Carta de Aurelio García y García a Nicolás de Piérola. Londres, 7 de octubre de 1883

78 BNP. Archivo Piérola. Sobre 5000000859. Carta de Aurelio García y García a Nicolás de Piérola. Londres, 17 de octubre de 1883. piarse de los fondos provenientes de la Compañía

el acuerdo económico ${ }^{79}$. Además, informó directamente al gobierno de Iglesias la ocurrencia de estas operaciones, pidiendo la destitución y cancelación de poderes de Rosas porque sus facultades como diplomático habían quedado canceladas por el nuevo ministro de Relaciones Exteriores, José Antonio de Lavalle $^{80}$. Al parecer, logró suspender la liquidación de la deuda de la mencionada empresa, pero falta mayor información para confirmarlo.

Después de la suscripción del tratado de Ancón (octubre de 1883), el gobierno de Iglesias con el apoyo chileno se trasladó de Trujillo a Lima. El canciller Lavalle propuso a García y García como el nuevo representante diplomático del Perú en Estados Unidos (que rechazó de plano) ${ }^{81}$ y en Inglaterra (puesto que finalmente aceptó). Días después, completamente aislado internacionalmente y fracturado internamente, el gobierno de Montero se desintegró y Arequipa cayó en manos del ejército chileno dirigido por el coronel José Velásquez ${ }^{82}$.

Ahora, como nuevo ministro en Inglaterra, García y García solicitó formalmente a la Peruvian Company detener cualquier operación del pago de la deuda hasta que el gobierno de Iglesias tomase conocimiento a profundidad de este asunto ${ }^{83}$. Estaba en estas gestiones cuando llegó un cablegrama que casi lo obliga a renunciar: sus credenciales diplomáticas no consignaban su grado de almirante otorgado por la Asamblea de Ayacucho (1881) y lo reducían solo a capitán de navío. Consideraba esto como un ultraje y así se lo comunicó a Lima ${ }^{84}$; más aún si estaba dedicado a resolver el asunto delicado de la deuda externa y la bancarrota del Perú ${ }^{85}$. Posteriormente, en 1884 , fue nombrado ministro plenipotenciario del Perú en la Santa Sede.

79 BNP. Archivo Piérola. Sobre 5000000859. Carta de Aurelio García y García a Nicolás de Piérola. Londres, 21 de octubre de 1883.

80 BNP. Archivo Piérola. Sobre 5000000859. Carta de Aurelio García y García a Nicolás de Piérola. Londres, 23 de octubre de 1883.
81 BNP. Archivo Piérola. Sobre 5000000859. Carta de Aurelio García y García a Nicolás de Piérola. Londres, 29 de octubre de 1883.

82 BNP. Archivo Piérola. Sobre 5000000859. Carta de Aurelio García y García a Nicolás de Piérola. Londres, 6 de noviembre de 1883.

83 BNP. Archivo Piérola. Sobre 5000000859. Carta de Aurelio García y García a Nicolás de Piérola. Londres, 17 de noviembre de 1883.

84 BNP. Archivo Piérola. Sobre 5000000859. Carta de Aurelio García y García a Nicolás de Piérola. Londres, 17 de diciembre de 1883.

85 BNP. Archivo Piérola. Sobre 5000000859. Carta de Aurelio García y García a Nicolás de Piérola. Londres, 10 de diciembre de 1883. 


\section{Conclusiones}

La importancia de la gestión de la información fue fundamental para Piérola en su estancia en Europa, aprovechó de la red de agentes diplomáticos y partidarios en Panamá (Federico Larrañaga), Francia (Toribio Sanz) e Inglaterra (Aurelio García y García) que le permitieron sostener su influencia política en el Perú. Aunque su ausencia tuvo un alto costo: la posición de abstención del Partido Nacional terminaría esquilmando la unidad entre sus miembros. Particularmente, Toribio Sanz tuvo un rol central en Europa, en plazas claves como Francia e Inglaterra entre 1880 y 1881 . Tras la caída de Lima hizo todo lo posible para continuar proveyendo de fondos al gobierno de Piérola en Ayacucho, mientras se enfrentaba a un diplomático que venía a reemplazarlo como parte de un nuevo gobierno: el civilista Francisco Rosas. Sin embargo, Sanz mantuvo el control de la legación hasta 1882 y tuvo el acceso a redes sociales y círculos gubernamentales que le permitieron a Piérola adaptarse rápidamente a París.

Por su parte, Federico Larrañaga fue un personaje protagónico en el control de una de las plazas más estratégicas de América: Panamá. Esta ciudad permitía el contacto entre las comunicaciones del gobierno peruano con sus legaciones en Europa y Estados Unidos, y era el punto de acopio y envío de armas hacia el Callao. Después de la caída de Lima pidió de fondos a Sanz para fundar el periódico El Canal, el principal portavoz pierolista en el extranjero, combatiendo a otros periódicos como La Actualidad (de los hermanos chilenos Castro) y El Orden (del gobierno de García Calderón). Desde ese entonces, el trabajo de Larrañaga fue lograr la subsistencia de El Canal (pago de redactores, imprenta, distribución, etcétera), llevándolo a realizar una serie de viajes por Venezuela, Centroamérica, Cuba y México para conseguir dinero. Sin embargo, la crisis del diario ya estaba declarada y fue cuestión de meses para que se concretara su desaparición por el agravamiento de la salud de Larrańaga y su posterior retorno al Perú en 1883.

Aurelio García y García fue un importante marino y político civilista que se hizo pierolista en el curso de la Guerra del Pacífico y ocupó también un papel fundamental en el recién creado Partido nacional (febrero de 1882). Tras la salida de Piérola hacia
Europa en marzo, el partido se encontró prácticamente a la deriva por la falta de acuerdo entre sus miembros y por el desconocimiento de la opinión del líder fundador residente en París. El empeoramiento de la crisis política en el país y la persecución de los líderes civilistas y pierolistas por las fuerzas chilenas, obligó a García y García a salir del Perú y se instaló en Londres, desde donde se comunicó y coordinó acciones con Piérola a lo largo de 1883, cerca al desenlace de la guerra y el advenimiento del general Iglesias, también un antiguo pierolista, como nuevo presidente impuesto por las bayonetas chilenas. A pesar del rechazo inicial por el lesivo tratado de paz, García y García aceptaría un puesto diplomático en Inglaterra y luego en la Santa Sede, es decir, se convirtió en funcionario del nuevo gobierno.

\section{Fuentes y referencias bibliográficas}

\section{Fuentes históricas}

Biblioteca Nacional del Perú

Archivo Piérola: Sobres 5000000759, 5000000859, 5000000862.

\section{Archivo Histórico Riva Agüero}

El Bien Público. Año II. Lima, sábado 31 de mayo de 1884.

\section{Referencias bibliográficas}

\section{Libros}

Aвanto, Julio (2012). Encarando el desastre. El conflicto hegemónico entre la burguesía limeña y los terratenientes serranos del norte en la guerra con Chile (1881-1884). Lima: Universidad Nacional Mayor de San Marcos.

Abanto, Julio (2017). El Congreso de la República durante la ocupación chilena. 1881-1883. Lima: Ediciones del Rabdomante.

BALLón, J. (2006). Blaine y Martí en la dialéctica de la Guerra del Pacifico. Ciudad de México, México: Universidad Nacional Autónoma de México.

Bruce, R. (1999). La política exterior del Perú. Lima, Perú: Asociación de Funcionarios del Servicio Diplomático del Perú.

De la Puente Candamo, J. \& De la Puente Brunke, J. (editores) (2016). El Estado en la sombra. El Perú durante la ocupación chilena. Documentos administrativos 
(diciembre de 1881-julio de 1882). Lima: Pontificia Universidad Católica del Perú.

García Belaunde, Víctor (2016). El expediente Prado. Lima: Asociación Civil Mercurio Peruano.

Garibaldi, R. (2013). Páginas diplomáticas del Perú. Lima, Perú: Asociación de Funcionarios del Servicio Diplomático del Perú.

Parodi, D. (2001). La laguna de los villanos: Bolivia, Arequipa y Lizardo Montero en la Guerra con Chile (1881-1883)

Guice, N. (1984). Crónicas de la Guerra con Chile (18811883). Lima: Mosca azul editores.

\section{Publicaciones periódicas}

Abanto, J. C. (2017a). La legación del Perú en los Estados Unidos de Colombia en la guerra con Chile (18791881). Memoria, Revista del Archivo General de la Nación de Colombia, (17), 36-48.

Aвanto, J. C. (2017b). Un empréstito internacional para financiar la guerra: el régimen de Lizardo Montero en Arequipa y el contrato Paz y Roselló (18821883). Documenta de Historia Militar de la Comisión Permanente de Historia del Ejército del Perú, (8), 79-92.

Aвanto, J. C. (2017c). La actividad de la Delegación de Lima en el contexto de la ocupación chilena de la capital (1881-1882). Revista del Archivo General de la Nación, (31), 181-196.

Авanto, J. C. (2014). Aportes para el estudio de la historia de la diplomacia del Perú: la actuación de la legación del Perú en los Estados Unidos en la Guerra del Pacífico (1879-1884). Nueva Corónica (4), 133-155.

Guice, Norman (1982). Giving Peru a Voice: Federico Larrañaga and El Canal de Panamá. The Americas. Vol. 39, No. 1 (Jul., 1982), pp. 85-106.

Pereyra, Hugo (2015). La negociación diplomática del Tratado de Ancón. Histórica, (XXXIX, 2). 153-170.

Trillo Auqui, Gerardo. (2015). Buenos Aires y la Guerra del Pacífico: actores subalternos en la ocupación de Lima. Diálogo andino, (48), 55-64. 